\title{
Visibility of Sri Lankan Publication in the Database of the Library of Congress
}

\author{
S. Ketheeswaren ${ }^{1}$
}

\begin{abstract}
Visibility of online catalogues will contribute data for many aspects such as creating uniform catalogues in libraries and ranking of libraries, authors, publishers, and institutions. The Cataloguing in Publication is the description of cataloguing the record for a book, which is obtained by the publishers just prior to their book publication for printing the same on the verso of the book title page while making them available online. Library of Congress provides online access to its Cataloguing in Publication and other catalogue data. The paper identifies the online visibility for catalogue data for the national publications in the Library of Congress. The finding shows that the coverage of national publications in the Library of Congress database is not satisfactory. A critical decline of online catalogue data from the LC is identified after the year of 2007, and the expected values for online catalogue record numbers for the year from 2007 to 2016 were measured using a fitting curve. Another finding of this study reveals that publications in the social science discipline get more online catalogue data from the LC. Necessary discussion and interpretation for these trends have been made throughout the paper using Tables and Figures.
\end{abstract}

Keywords: Authority control, Bibliographic control, and Cataloging in Publication

\footnotetext{
${ }^{1}$ Senior Assistant Librarian, University of Jaffna, Email: vskethees@ gmail.com (1) https://orcid.org/0000-0002-0892-5089 


\section{Introduction}

The visibility of publications of a country or individual depends on the bibliographies, indexes etc. which provide the necessary data for searching. In this scenario, the data for cataloguing secondary literature, for example the books, is basically collected from the records of Cataloguing in Publication (CIP). The CIP is the bibliographic description printed on the verso of the title page of a book. The CIP is usually prepared by a national body of a country. In Sri Lanka, the National Library and Documentation Services Board has been preparing the CIP for the national publications since 1996, (National Library of Sri Lanka, 2017). In the U.S.A, CIP is prepared by the Library of Congress (LC). The Library of Congress prepares CIPs for the request of the publishers to serve its nation's libraries by cataloguing books in advance of publication (CIP Library of Congress, 1971).

The regional office of the Library of Congress in Colombo does not have direct involvement in issuing CIP data by the Library of Congress for the publications in Sri Lanka. The regional office contributes for the online visibility of Sri Lankan publications in the database of the Library of Congress; the regional office of the Library of Congress in Colombo is periodically collecting and sending the national publications of Sri Lanka to be catalogued and housed in the Library of Congress. Then, its details of bibliography are made available in the online catalogue of the Library of Congress. Regional office of the Library of Congress in Colombo does not collect the publications of general theories and the publications without national distinctiveness, for the purpose of archival in the Library of Congress in Washington. In case, a publisher or an author affiliated to Sri Lanka has collaboration in a publication with an agency in the USA, the CIP data may be prepared by the Library of Congress as a publication in Sri Lanka (D. Daniel, personal communiation, January 26, 2018).

The availability of online catalogue of the Library of Congress helps for authority control practices in libraries while increasing the online visibility of publications of the publishers and authors.

It can generally be observed that most of the publications from the western world have their CIPs printed on the verso of the title pages, while making all of them available online. It is observed that the Sri Lankan publications 
have the local CIPs printed in the books; but there is no literature found to identify whether the Sri Lankan Publications do have the z39.50 (data communication protocol for bibliographic information) distributions for the CIP data or national bibliography. In these observations, studies on the visibility of national publications in the collections of online records of the Library of Congress, one of the leading agencies in housing international publications, has provided ground information about its coverage together with other conclusions and recommendations. The present study investigates the inclusion of the CIP data and bibliographic data for Sri Lankan publications in the LC database for worldwide visibility.

\section{Research Objectives}

The objectives of this study were to;

i. Find out the status of national publications in the online catalogue data of the Library of Congress

ii. Find out the growth rate of online catalogue data of the Library of Congress for Sri Lankan Publications

iii. To find out the impact of the subject coverage on the visibility of publication in the z39.50 target of the LC

\section{Literature Review}

Primarily, Struble and Kohberger (1987) have carried out a similar study under the title "Statistical survey to determine availability of cataloging Copy on OCLC"'(Online Computer Library Center). They determined what level of cataloging copy is present on OCLC at the time an item is received in Technical Services and after a six-month waiting period, (Struble \& Kohberger, 1987).

Many of the other authors concentrated on authority (bibliographic) controls of CIP records. Zeng (1991) studied the impact of automation of bibliographic control using the Library of Congress index for Chinese materials. Deborah E. Kulczak (2000) examined the authority work using indexes for OCLC copy cataloguing (Kulczak, 2000). Richard P. Smiraglia (2004) undertook a study on finding the possibility of implementing authority control of works using cataloguing indexes. 
Few authors have done studies on copy-cataloguing, which has some relevancy to the present study. O'Neill and McClain (2001) looked at how both the Library of Congress index and the Dewey Decimal call numbers are used by the OCLC member libraries, (O'Neill \& McClain, 2001). The paper of McCutcheon (2012) provided the concept of policies with the information needed to establish standards for copy cataloguing RDA records for particularly monographs.

\section{Methodology}

The study needs the online data of Sri Lankan publications. Preliminary interest of the study is to get a basic understanding of the coverage of bibliographic data of Sri Lankan publications online. Therefore, a leading agency for providing online catalogue data service should be selected. The literature survey provided the information that the Library of Congress stating that it first started the practice of issuing CIPs in 1971 and hosted many online catalogue data for international publications (Zarei, 2012). Thus, online catalogue data was collected from the Library Congress for all Sri Lankan publications by searching the Library of Congress Online Catalogue (Catalogue of Library of Congress, 2007). The searches were made by filtering the place of publication using the term "Sri Lanka" (Catalogue of Library of Congress, 2007). The searched records were downloaded as Machine Readable Catalogue (MARC) formats. The MARC data was then encoded to Tab Delimited Records using the MARC edit software. The selected MARC tags for the process were $245 \$ a, 050 \$ a, 260 \$ c$ and $264 \$ c$ based on the purpose of this study. The Tab Delimited Records were then imported to an Excel sheet applying the rules of UTF-8. The subject coverage of the online catalogue data was identified by using the Library of Congress Subject Headings. Using the functions of the software available, the data were processed and necessary tables and figures were plotted.

\section{Results and Discussion}

According to the statistics available in the national bibliographies for the publications of the years 2011 to 2015, approximately 27900 publications have been published in Sri Lanka. However, overall Sri Lankan publication records from the Library of Congress database is 366 in numbers covering 
the period from 1960 to 2016 , a period of 56 years. This is obviously a very low number compared to the total number of publications published during the 56 years. Hence, the contribution for the availability of CIP and online catalogue data in the Library of Congress for national publications is very low. Therefore, the libraries in Sri Lanka are in need of a system for online catalogues of the national publications to prepare and maintain standard and uniform catalogues amongst the libraries.

The Figure 1 shows that year wise online catalogue data available in the LC shows peaks and troughs throughout the years and it has the highest value at the year of 2007 and declines after the year 2007. It proves that the mechanism for availability of online catalogue data is not steady. The current trend, after the year 2007, is more critical. It is important that the necessary instruction or awareness should be given to the commercial publishers, author publishers, and institutions in order to increases the online catalogue data.

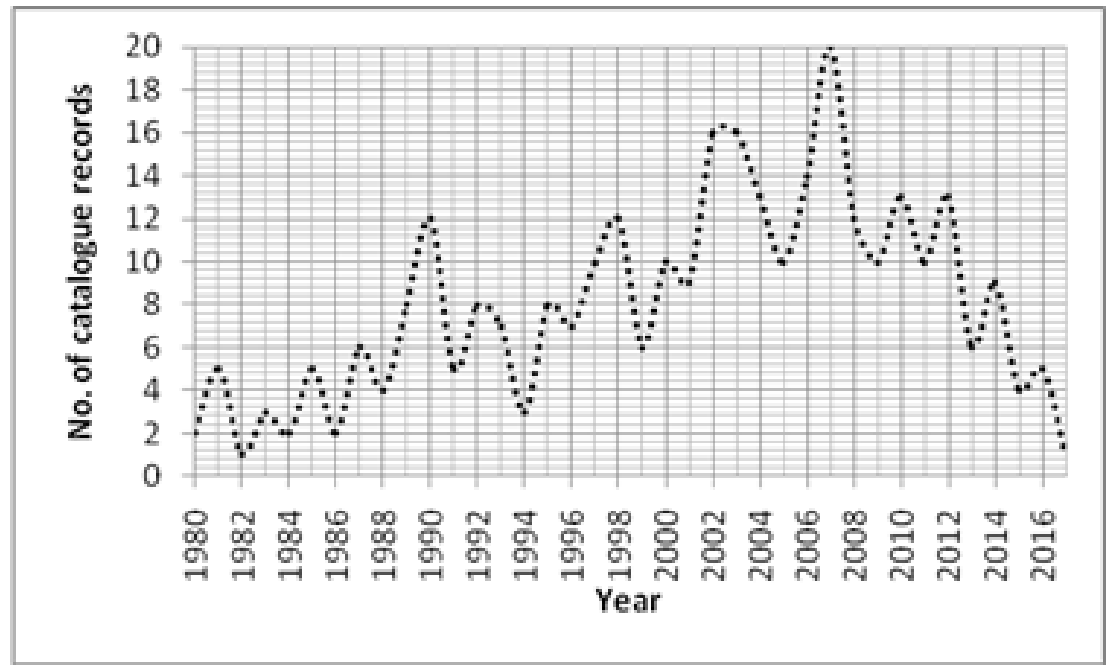

Figure 1. Year-wise trends for avilabilty of online catalogue records of Sri Lankan publications in the LC database.

Figure 2 shows the best fit of exponential growth for online catalogue records from year 1980 to the peak year 2007. The year 1980 is set to zero to minimize the deviation of $\mathrm{x}$ and $\mathrm{y}$ values, in order to get a good fitting curve. The exponential fitting curve becomes $f(x)=2.383 e^{0.073 x}$ 


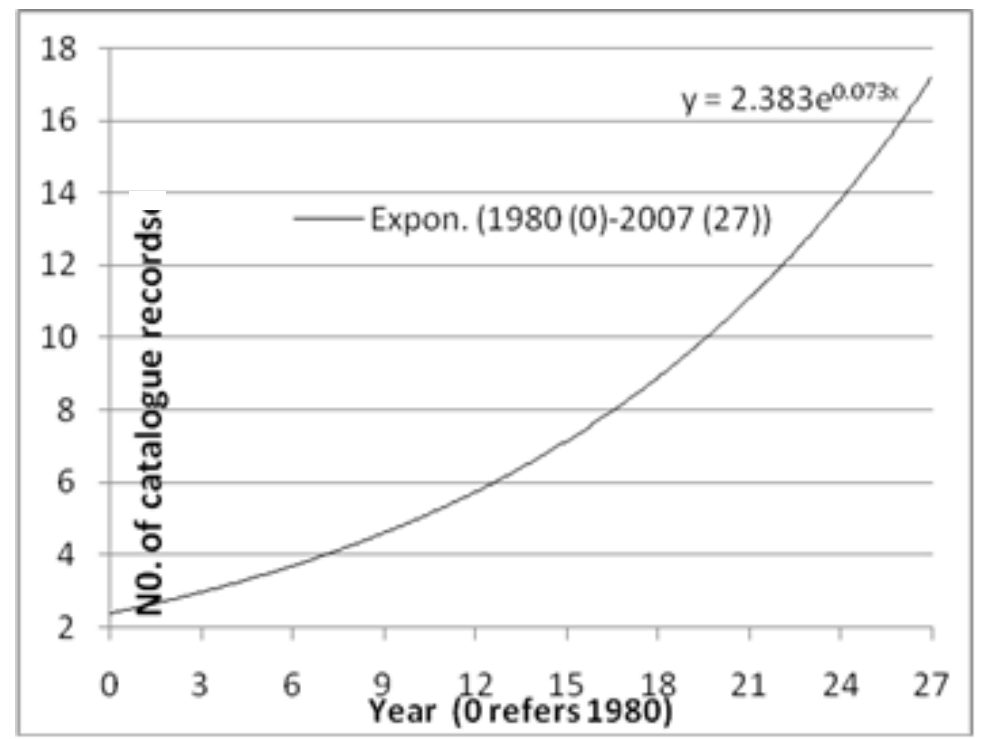

Figure 2. Year-wise growth of online catalogue records of Sri Lankan publications available in the LC database, upto the peak year 2007

After the year 2007 the expected number of online catalogue records can be calculated using the fitting equation $f(x)=2.383 e^{0.073 x}$ of the data between the year 1980 and 2007, for which exponential growth is observed.

Table 1 shows the expected values calculated using $f(x)=2.383 e^{0.073 x}$ and the values obtained through data collection. The expected value after the year 2007 should be increasing exponentially according to the trends of the years between 1980 and 2007 and the 33 online catalogue records should be observed at the last year point 2016 .

However, 5 online catalogue records are collected for the year 2016 in reality and all online catalogue data after the year 2007 are observed to be declining as seen in the Figure 3. 
Table 1. Data collected and predicted of the years between 2007 and 2016

\begin{tabular}{lcc}
\hline Year & Data ollected & $\begin{array}{c}\text { Value of } \\
\end{array}$ \\
\hline 2007 & 20 & $2.383 e^{0.073 x}$ \\
2008 & 12 & 17 \\
2009 & 10 & 18 \\
2010 & 13 & 20 \\
2011 & 10 & 21 \\
2012 & 13 & 23 \\
2013 & 6 & 25 \\
2014 & 9 & 27 \\
2015 & 4 & 29 \\
2016 & 5 & 31 \\
\hline
\end{tabular}

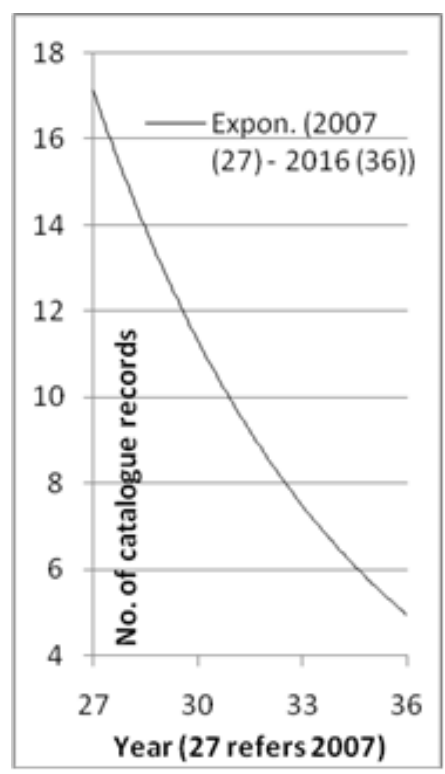

Figure 3. Year-wise exponential decline of online catalogue records of Sri Lankan publications after the peak year 2007. 
Usually the CIP data is obtained by the publishers prior to the publication (CIP Library of Congress, 1971). Therefore, time required for the visibility of the CIP in the LC database after publication is zero. The reason for the trend may be two folds; one is the sudden change of attitude of putting the bibliographical data in the CIP database of the LC, and another is the period of years required to collect and send the national publications by the regional office in Colombo and to put its catalogue data available online in the Library of Congress database.

The awareness of CIP records and its usefulness to maintain a uniform catalogue in libraries and increase the visibility for the ranking of libraries, authors, publishers and institutions should be understood and measures should be taken to increase the availability of online records in the LC database and/or other bibliographic database/s for national publications. Based on this background, the subject-wise trends for the availability of online catalogue data should be studied to analyze the subject-wise contribution and awareness of publishers.

Figure 4 shows the subject wise trends for the availability of catalogue data in the LC database, whereas the subjects in letters taken from the Library of Congress Subject Headings, (LC Suject Heading, 2007). The Library of Congress classification outline has a subclass of subjects: Economics, Transportation, Commerce, Finance, Sociology, Social Pathology, Socialism, Communism etc. for Social Science and has a subclass of subjects: History of Civilization, Archeology, Diplomatic, Technical Chorology, Numismatics, Inscriptions, Biography etc. for Auxiliary Science of History (LC Suject Heading, 2007).

According to Figure 4, the highest numbers of catalogue records are available in the LC database for the publications under the discipline of Social Science and it becomes more than double the value of the second highest which is Auxiliary Science of History. It says that the publications in the field of Social Science have a great contribution for the online catalogue data in the Library of Congress. At the same time, the contribution from the field of Science becomes weak where Science has more visibility in the indexes of primary literature in Sri Lanka. This is due to the selection criteria 
of the Library of Congress regional office in Colombo. They are collecting the publications reflecting on national distinctiveness, most probably the Social Science subjects and they are not collecting the publications of general theories, most probably the Science subjects for the purpose of archival in the Library of Congress.

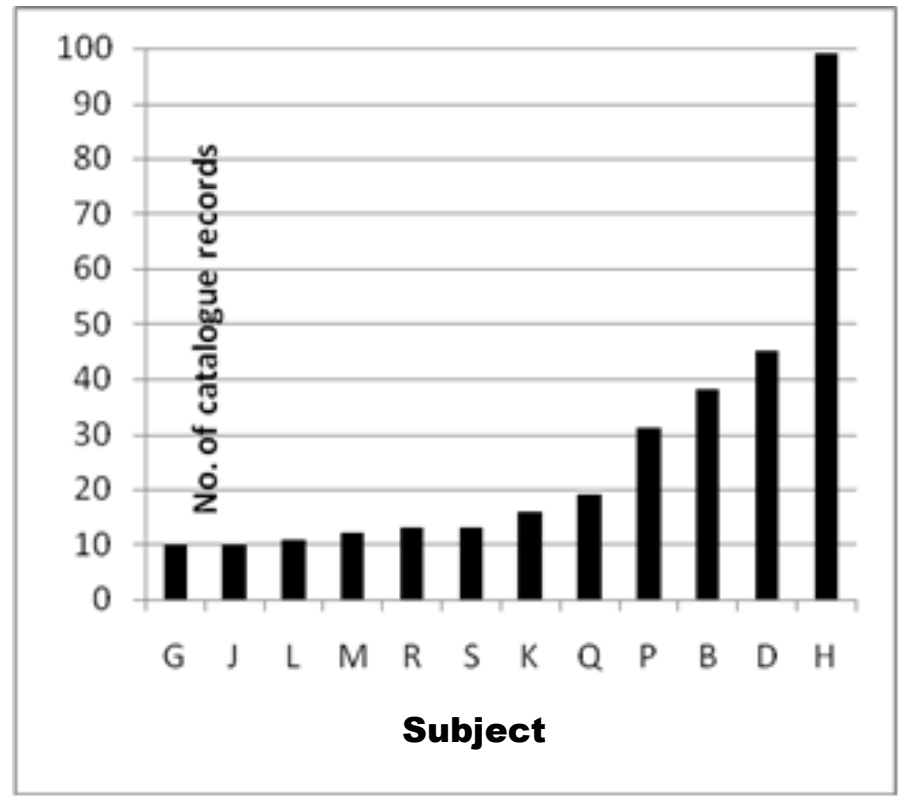

Figure 4. Subject-wise distribution on avilabilty of catalogue records of Sri Lankan publications, in the LC database

Note. Subjects in letters taken from the Library of Congress Subject Headings: BPhilosophy, Psychology and Religion; D - Auxiliary Science of History; G-Geography; HSocial Sciences; J-Political Science; K-Law; L-Education; M-Music; P-Language and Literature; Q-Science; R-Medicine; S-Agriculture

Figure 5 presents the subject-wise trends of top four subjects contributed for the availability of CIP data in the LC. Social Sciences, Auxiliary Science of History, Philosophy Psychology and Religion, and Language and Literature have been identified as top four disciplines contributing to the online catalogue of the Library of Congress. From Figure 5, we can observe that the discipline of Social Science is dominant as CIP peak contributions at the year of 2007 and its overall contribution is also large as seen in Figure 4. It gives an indication that many publishers and authors in the field of Social Science 
have the intention of publishing CIP data in the LC database. And also the publications in the field of Social Science in the country are most welcome by the regional office of the Library of Congress in Colombo to be catalogued and housed in the Library of Congress in Washington. It also provides evidence that publication counts in the county in the fields of Social Science should be high as compared to the other fields.

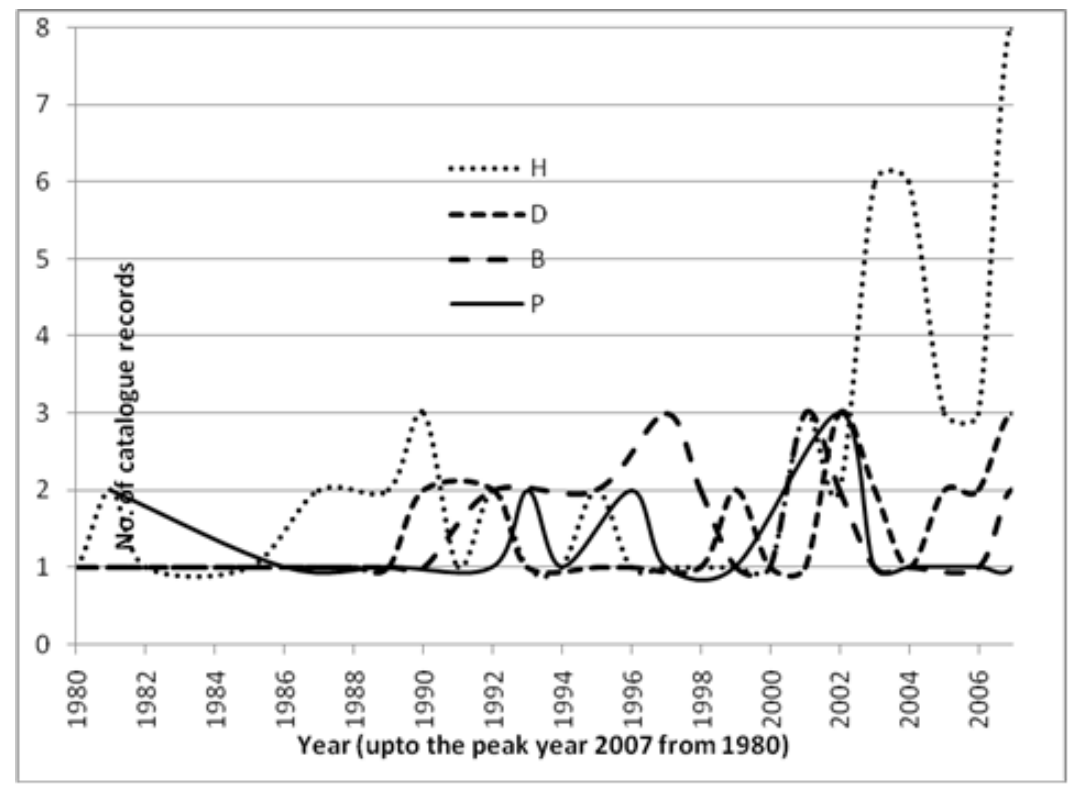

Figure 5. Subject-wise trends for avilabilty of CIP records of Sri Lankan publications in the LC database, for the subjects Social Sciences, Auxiliary Sciences of History, Philosophy Psychology and Religion, and Language \& Literature

Figure 5 illustrates that all publications of these four subjects have a peak contribution for catalogue records in the LC in the year of 2007 as similar to the combined curve (Figure 1) plotted irrespective of subject coverage. It can be envisaged that there would have been any CIP record raising awareness programme during the years of 2006 and 2007. The Library of Congress office in Colombo has not documented any record raising awareness programme during the years of 2006 and 2007, but it informs that managerial changes occurred in the office in 2007 and it may be one of the reasons for the observation of the peak. 


\section{Conclusion}

Study identified certain patterns and predictions on the availability of catalogue data in the online catalogue of the Library of Congress. In order to prepare and maintain a uniform catalogue amongst the libraries in Sri Lanka, a common system for distributing online catalogues of the national publications should be available. The publishers and authors in the country do not have an awareness or interest on online CIP data. The personal communication with the National Library and Documentation Services Board of Sri Lanka has brought to light that there is nation-wide policy restriction for the publishers and authors to continue with the online CIP data prior to their publications. If an author or publisher would request for CIP data, the National Library and Services Board will work on providing CIP data for their publications. Another finding from the study is that the mechanism for the availability of online catalogue data in the Library of Congress for national publications is not steady. The policy makers in the field of Library and Information Science should emphasize the importance of maintaining uniform catalogues in national libraries by contributing data for online CIPs and using copy-cataloguing for controlled catalogue entries. The usage of online catalogue is not only to maintain uniform catalogues, but also for increasing the visibility of local publications internationally. The international visibility will enrich the values of ranking indicators used to measure the nation-wide productivity of authors, publishers, and institutions. Therefore, necessary measures need to be taken to encourage the book publishers and national agencies to transfer their CIP data available in an online database prior to their publications which will enrich the online CIP data for the country in future.

The results of the study further show that the current trends, after the year of 2007, have a decline in the availability of online catalogue data in the LC. However, the initial trend observed by the data from 1980 to 2007 shows that the CIP data was growing exponentially. Though CIP data from 2007 to 2016 too should be increasing according to the collected data, it is identified to be declining. It may be due to the processing time required for getting and sending the national publications by the regional office of the Library of Congress in Colombo. Similar studies should be conducted incorporating other international online CIP data systems like OCLC WorldCat, British Library etc. to find out the trends for Sri Lankan publications. 
A significant finding from this study is that the publications in the social science discipline get more catalogue data from the LC. The reason for this fact is that the books published in the field of Social Science have a high tendency in the book selection policy of the regional office of the Library of Congress as the social science discipline mostly represents national distinctiveness expected by the regional office. Further, publication-count in the fields of Social Science is generally high in the country. The scheme and methods of obtaining the CIP data for the LC should be studied, analyzed further and the information has to be transferred to the publishing community.

\section{References}

Catalog of Library of Congress. (2007). Online Cataloug. Retrieved from https://catalog.loc.gov/vwebv/searchAdvanced?editSearchId=R

CIP Library of Congress. (1971). Cataloging in Publication program, Retrieved from https://www.loc.gov/publish/cip/

Kulczak, D. E. (2000). Name authority work for OCLC copy cataloging: Is it worth the effort? Cataloging \& Classification Quarterly, 28(1), 69-81. doi: 10.1300/J104v28n01_07

LC Suject Heading. (2007). Library of Congress classification outline. Retrieved from https://www.loc.gov/catdir/cpso/lcco/

McCutcheon, S. (2012). Designing policy for copy cataloging in RDA. Library Collections, Acquisitions, \& Technical Services, 36(3-4), 69-78. doi: 10.1080/14649055.2012.10766331

National Library of Sri Lanka. (2017). Cataloguing-In-Publication (CIP). Retrieved from http://www.natlib.lk/index.php/cataloguing-inpublication-cip

O'Neill, E. T., \& McClain, P. (2001). Copy cataloging practices. Journal of Library Administration, 34(1-2), 93-102. doi: 10.1300/J111v34n01_15 
Smiraglia, R. P. (2004). Authority control of works: cataloging's chimera? Cataloging \& Classification Quarterly, 38(3-4), 291-308. doi: 10.1300/J104v38n03_22

Struble, C. A., \& Kohberger, P. B. (1987). Statistical survey to determine availability of cataloging copy on OCLC. Cataloging \& Classification Quarterly, 7(3), 13-22. doi: 10.1300/J104v07n03_03

Zarei, H. (2012). Comparison of Cataloging in Publication (CIP) with Cataloging-after-Publication (Opac) of Iran National Library Bibliographic Center. Library Philosophy and Practice, 8(1), 794.

Zeng, L. (1991). Automation of bibliographic control for Chinese materials in the United States. International Library Review, 23(4), 299-319. doi: 10.1016/0020-7837(91)90002-H 